\title{
MODERN VIEWS \\ ON THE MANAGEMENT OF PLACENTA PRAEVIA
}

\author{
By C. H. G. Macafee, M.B., F.R.C.S.(Eng.), F.R.C.S.I., F.R.C.O.G.
}

Professor of Midwifery and Gynaecology, The Queen's University, Belfast. Gynaecologist, Royal Victoria Hospital, Belfast. Surgeon, Royal Maternity Hospital, Belfast

The treatment of placenta praevia up to recent years has been seriously influenced by the belief that once the complication manifests itself by haemorrhage immediate treatment should be undertaken. This approach to the subject has resulted in a maternal mortality of 5.7 per cent. and a foetal mortality of $50-60$ per cent. (Browne and Comyns Berkeley).

In a personal series of 275 cases supervised over a period of 13 years 56 babies were stillborn or died. Of these, 30 babies were lost in the first four years while the writer was endeavouring to alter the traditional line of treatment.

\section{TABLE I}

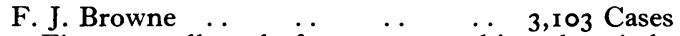

Figures collected from II teaching hospitals in Great Britain

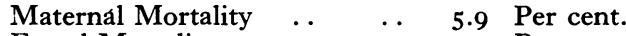

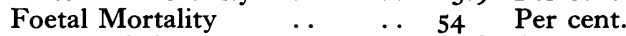

Sir Comyns Berkeley ... . . . . . 4,580 Cases

Hospitals, Great Britain, Northern Ireland and Eire

Maternal Mortality .. $\quad$. 77 Per cent. Foetal Mortality (S.B. or died) 59 Per cent.

Stratz

$\begin{array}{cccc}\text { Maternal Mortality } & \ldots & . & \text {. } 73 \text { Cases } \\ & & 0.57 \text { Per cent. }\end{array}$

Foetal Mortality $\quad . . \quad \ldots \quad 44 \quad$ Per cent.

Royal Maternity Hospital, I932-1936 76 Cases

Belfast

Maternal Mortality .. $\quad$. 2.6 Per cent.

Foetal Mortality (S.B. or died) $5 \mathrm{I} .3$ Per cent.

Royal Maternity Hospital, Belfast,

to 937 January 8th, I949
(Including 33 private cases)

Maternal Mortality (2 cases) ..

Gross Foetal Mortality (56 cases) (S.B. or died) $\quad \ldots \quad 20.4 \quad$ Per cent.

Number of Still-Births and Neonatal Deaths in EACH YEAR

\begin{tabular}{|c|c|c|c|c|c|c|}
\hline 1937 & .. & & . & . & $10\left(5^{8}\right.$ & Per cent. \\
\hline 1938 & . & . & .. & .. & $7(43$ & ", \\
\hline I 939 & . & . & . . & . & $7(3 \mathrm{I} .8$ & ," \\
\hline 1940 & .. & . & .. & . & $6(29.4$ & ," \\
\hline I 94I & $\ldots$ & . & .. & . & $0(0$ & ," \\
\hline 1942 & . & . & .. & . & $4(17$ & , \\
\hline 1943 & . & . & .. & . & $3(\mathrm{II} .5$ & , \\
\hline 1944 & . & . & .. & . & $3(16.6$ & ", \\
\hline 1945 & $\ldots$ & .. & .. & . & $3(13$ & $"$ \\
\hline
\end{tabular}

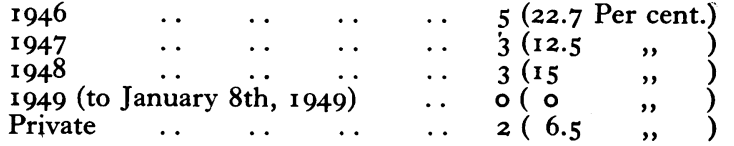

The object of all recent workers has been to reduce the foetal mortality, a large proportion of which has been due to prematurity, without adding to and, if possible, reducing the risk to the mother. It is obvious that reduction of the foetal mortality due to prematurity requires a method of treatment which will permit of the delivery of a mature or relatively mature infant.

While prematurity is one of the most important causes of the foetal mortality in placenta praevia there are certain other factors over which there is little control. The anatomy of the placenta in placenta praevia is an important cause of intrauterine death or death of the foetus during labour. A placenta praevia is usually a thin placenta which covers a large area of the uterine cavity and it is frequently lobulated. In addition, the umbilical cord often has an eccentric or velamentous insertion which in itself is an added risk.

If the cord is inserted at the lower edge of the placenta in close proximity to the internal os the first haemorrhage may cause the death of the foetus. Its situation in this region is also associated with the added risk of prolapse when the membranes are ruptured spontaneously or artificially.

If a velamentous insertion of the cord is present one or more of the umbilical vessels may cross the internal os and spontaneous rupture or accidental damage of these vessels will result in death of the foetus. In analysing the cause of death in 47 babies it was found that in 13 cases the situation of the cord was the primary factor.

TABLE 2

Cause of Death in 47 Babies

Private .. I low insertion of cord, baby died following haemorrhage.

I $\mathrm{s} / \mathrm{b}$, first twin; prolapsed cord; low insertion of cord. 
I937 .. I version. Difficulty with after-coming head.

I version, as baby small.

I baby died after initial haemorrhage.

3 versions.

I velamentous insertion of cord. Willetts forceps.

2 premature I lb. I oz. and $3 \mathrm{lb}$. $10 \mathrm{oz}$.

1938 I I Willetts forceps applied Type III. Error of judgment.

I version; child could not be resuscitated, although heart beating.

I A.R.M. and Willetts forceps.

I intra-uterine death.

3 premature.

$1939 \quad$.. I prolapsed cord and version.

I version done unnecessarily.

I cord inserted at lower edge placenta. Baby died following fifth haemorrhage.

I breech foot extracted.

r940 .. I velamentous insertion of cord, one vessel ruptured during A.R.M.

I Battledore insertion cord at lower edge of placenta. Willetts forceps applied, and later found to have caught cord. Error of judgment.

I following panicky version; some difficulty in delivery of after-coming head.

2 premature at 28 and 32 weeks.

I942 .. I velamentous insertion with rupture of one vein. Version.

I death of baby after haemorrhage, cord inserted immediately over separated area of placenta.

I child born enveloped in placenta.

I premature at 32 weeks.

r943 .. I version low insertion of cord.

1944 .. I premature, 3 lb. 4 oz., 30 weeks. Type III P.P.

I premature, 3 lb. 3 oz. Baby dead on admission.

I945 .. I premature, 3 lb. 8 oz. Transverse presentation ; prolapsed cord ; version.

I s/b at Caesarean section. Foetal heart poor before operation, following severe haemorrhage ; cord insertion over area of separation.

I neonatal death - scleroderma.

I946 .. I s/b at section, following severe haemorhage.

I s/b at section. Foetal heart very weak and irregular before operation.

I neonatal death. Intra-uterine asphyxia and prematurity.

I neonatal death. Icterus gravis.

I neonatal death. Cyanotic attacks.

1947 .. I neonatal death. Prematurity.

I neonatal death (four hours after birth). Child anaemic. Torn vasa praevia.

I neonatal death. Prematurity.

1948 .. I neonatal death. Prematurity.

I s/b. Leg brought down.

Another factor over which one has no control is the incidence of foetal abnormalities. The association of a high rate of foetal abnormality with placenta praevia has long been recognized. The incidence of this occurrence in the personal series was 3.6. per cent.
TABLE 3

Cases Eliminated for Correction of Foetal MORTALITY*

\begin{tabular}{|c|c|c|}
\hline & Still-Births & Neonatal Deaths \\
\hline I 937 & I hydrocephalic & - \\
\hline I 939 & $\begin{array}{l}2 \text { anencephalic } \\
\text { macerated foetus, } \\
\text { I lb. } 2 \mathrm{oz} \text {. }\end{array}$ & \\
\hline 1940 & $\div$ & $\begin{array}{l}\text { I gastro-enteritis } \\
\text { days after delivery }\end{array}$ \\
\hline I 943 & I anencephalic & I gastro-enteritis \\
\hline 1944 & 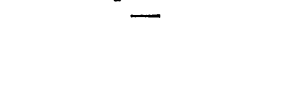 & $\begin{array}{l}\text { I gastro-enteritis } \\
\text { days after delivery. } \\
\text { Weighed } 8 \text { lb. Io } \\
\text { oz. at delivery. }\end{array}$ \\
\hline I 948 & I anencèphalic & - \\
\hline
\end{tabular}

(Corrected foetal Mortality I7.I per cent.)

In addition to the above abnormalities, there was one mongol, one spina bifida, one cleft palate, and one congenital cataract, which survived.

Incidence of foetal abnormalities, 3.6 per cent.

* Seven premature babies under $3 \mathrm{lb}$. have not been eliminated, as the prematurity was due to the placenta praevia.

One case of icterus gravis and one case of scleroderma have not been eliminated.

The maternal death rate, when immediate treatment was the practice, was due to shock and haemorrhage. When one considers that in the majority of cases the cervix is closed at the time of the initial haemorrhage and that the popular method of treatment was version, it is not surprising that the maternal and foetal mortality was so high. Stratz (Table I), however, records I73 cases where vaginal methods of delivery alone were employed with a maternal mortality (one case) of 0.57 per cent. His foetal mortality rate was, however, 44 per cent.

Recent workers, Johnson ${ }^{1}$, Mills $^{2}$ and Macafee $^{3,4}$ have advocated the use of expectant treatment in cases of placenta praevia where the haemorrhage is slight and occurs when the baby is immature. The published series of cases by Johnson and Mills and the personal series of 275 cases represent $45^{1}$ cases with two maternal deaths, a maternal death rate of 0.46 per cent., and an uncorrected average foetal mortality rate of approximately 20 per cent.

Those writers (Sturrock, Stirling and Tennent) ${ }^{5}$ who defend immediate interference do so on the ground that expectant treatment makes a heavy demand on already overtaxed antenatal departments, that it is not without danger to the mother, and that it cannot be shown to improve the prospects for the baby.

While antenatal departments may be overtaxed the number of cases of placenta praevia requiring expectant treatment at any one time is relatively small. Over a period of five years 122 cases were admitted to the Royal Maternity Hospital, 
Belfast. Of these, 45 cases ( 36.8 per cent.) or nine per year, have had more than seven days deliberate expectant treatment. The length of this expectant treatment varied from 8-103 days. Of the 45 babies 9 weighed less than $5 \mathrm{lb}$., and there were 7 stillbirths or neonatal deaths, a gross foetal mortality of 15.5 per cent. There was one anencephalic foetus and one case of icterus gravis. If one eliminates only the anencephalic foetus the corrected foetal mortality is 13 per cent., which is better than the corrected mortality for the entire series. If immediate treatment had been carried out on all these 45 cases many more babies would have been lost.

TABLE 4

Placenta Praevia

Hospital and Private Cases

I 944-1948 (inclusive)

Total Cases

.. $\quad \ldots \quad \ldots \quad 122$

Cases having more than seven

days deliberate expectant treat-

ment :

8-103 days .. $\quad \ldots \quad \ldots \quad 45$ (36.8 Per cent.) ( 9 babies weighed less than 5 lb.)

Still-births and neonatal deaths.. 7 (15.5 , )

(Eliminating one anencephalic) .. $6(13.5$, ,

The contention that expectant treatment, even in hospital, is not without danger to the mother is reasonable and has some support in fact. All who advocate expectant treatment, including the writer, state that the initial haemorrhage is unlikely to be catastrophic and that a really serious haemorrhage has usually been associated with vaginal manipulations.

Since subscribing to this belief in 1945 the writer has seen at least two serious haemorrhages occur, one in a primigravida and one in a multipara, where no vaginal examinations had been made. Both mothers survived but one baby was dead. In the writer's series of 275 cases two mothers have died, one from a staphylococcal septicaemia following a Caesarean section, and one from an incompatible ( $R$ h) blood transfusion. Both of these deaths might have been avoided if sulphonamides or penicillin had been available in one case, and if a true history had been obtainable at the time of transfusion in the other. There was no death from shock or haemorrhage.

Before deciding on expectant treatment each case must be considered individually, and only those cases which are suitable should be treated expectantly. To embark upon expectant treatment where the inital haemorrhage, or the haemorrhage for which the patient has been admitted, has occurred between 37 to 40 weeks gestation is neither justifiable nor safe. As a general rule these cases should be treated on admission as delay merely increases the risk of both mother and child and can in no sense be justified where the foetus is already of adequate maturity.

The case in which expectant treatment is most valuable is the one where a small haemorrhage has occurred at 30 to 34 weeks, where the baby is premature and where the baby's chance of survival is much improved if the pregnancy can be prolonged three to four weeks. An additional and important factor is the amount and duration of the haemorrhage.

In placenta praevia the haemorrhage is of sudden onset, but in many cases stops almost as quickly as it started. Therefore, if the loss persists for some hours, even though it is not of large amount at any one time, it is unwise to continue expectant treatment. A prolonged bleeding of this nature results in the patient suddenly becoming ill without other warning signs.

Having decided on expectant treatment the patient should be confined to bed for a few days during which time an attempt should be made to arrive at a clinical diagnosis and a complete blood examination, $\mathrm{Hb}, \mathrm{ABO}$ and $\mathrm{Rh}$ grouping, should be carried out.

After experience of a number of cases it is surprising how a relatively accurate diagnosis can be made from the findings on abdominal palpation, not only of the presence of a placenta praevia, but also of the degree.

Browne ${ }^{6}$ has divided placenta praevia into four degrees, and while many authorities consider that this is of purely academic interest, the writer has found the division of great value in deciding on a line of treatment.

In the personal series of 275 cases the incidence of the first and second degrees is about the same as that of the third and fourth. In the first and second degrees there were 138 cases, and in the third and fourth 137 .

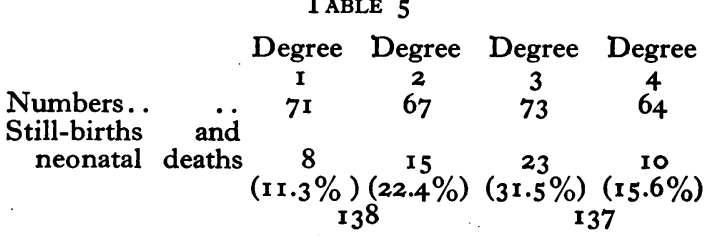

On abdominal palpation the level of the presenting part varies with the degree of placenta praevia and the period of gestation. In a minor degree (say first or second) the vertex can be pushed into the brim of the pelvis, while in the more severe degree (third and fourth) the head lies above the symphysis pubis or may lie in one or other iliac fossa even in a primigravida. The ease with which the presenting part can be felt is an 
indication as to whether the placenta lies anteriorly or posteriorly.

lt has been stated in most textbooks that placenta praevia is associated with a breech presentation. This is a rare finding, but when present the breech, owing to its soft consistence, may add to the difficulty in making an accurate diagnosis.

A vaginal examination should not be made until the termination of expectant treatment, but a vaginal speculum should be passed and the cervix and vagina inspected to exclude local causes of vaginal haemorrhage.

$\mathrm{X}$-ray pictures of the abdomen should be taken to exclude those foetal abnormalities demonstrable by radiography and, if the special soft tissue technique can be employed, the position of the placenta may be demonstrated. Even when small recurrent haemorrhages do occur it seems to be safe to wait until the baby is reasonably mature before embarking on active treatment.

For prolonged expectant treatment the co-operation of the patient and her husband is essential. The time taken in explaining the position fully to both is well spent and the husband should be warned that treatment at short notice may be necessary without his knowledge or consent.

\section{Active Treatment}

This must be carried out in the following circumstances :-

I. Where the patient has been admitted on account of antepartum haemorrhage between 37 weeks and full term. As has been mentioned, there is nothing to gain and much to lose by waiting.

2. In any patient receiving expectant treatment where the pregnancy has reached 38 weeks.

3 . In the presence of a more than moderate haemorrhage, or where even a slight haemorrhage persists for some hours.

Active treatment may not entail more than a vaginal examination but the findings at this examination may indicate that a Caesarean section is necessary. Therefore, the examination should be performed on the operating table with everything, including compatible blood, available. While there is some difference of opinion regarding the use of anaesthesia. for this examination, the writer always examines the patient under light cyclopropane and oxygen, the patient being kept in the first plane of anaesthesia. This permits of a more accurate examination and therefore one is more likely to arrive at the correct decision without distressing the patient. If a Caesarean section should be necessary the operation should be proceeded with immediately, as any undue delay will result in depression of the foetal respiratory centres.

Every examination should be started with an open mind because treatment depends on many circumstances. The introduction of the half or whole hand into the vagina as advised by some writers is quite unnecessary. One or two fingers in the vagina will give all the information required. In a primigravida the cervix may not be effaced and there may be no dilatation so that one depends on the ease with which the presenting part can be felt through the vaginal fornices. If it can only be felt easily through one of the four fornices and is lying high at or above the level of the pelvic brim then a Caesarean section is the best method of treatment. On the other hand, if it can be palpated easily through three fornices, and there is still some doubt about the fourth, the patient should be returned to bed, provided no haemorrhage occurs, and the onset of labour awaited. In such a case haemorrhage may recur early in the first stage, but in most cases this can be controlled by artificial rupture of the membranes.

In a multipara the cervix is frequently dilated to such an extent that the lower uterine segment can be explored with the index finger. The treatment then will depend on the degree of placenta praevia, the previous obstetric history and the presence or absence of any associated abnormality. In the minor degree of placenta praevia (one or two) artificial rupture of the membranes will usually be sufficient in a patient with a history of easy rapid deliveries, but should the previous obstetric history be doubtful or the cord prolapse a Caesarean section should be performed. In the third or fourth degrees Caesarean section is advisable, but if the baby is premature or has died in utero and the placenta is of the third degree, podalic version must be considered.

TABLE 6

\begin{tabular}{|c|c|c|c|c|c|c|}
\hline $\begin{array}{l}\text { De- } \\
\text { gree }\end{array}$ & A.R.M. & $\begin{array}{l}\text { A.R.M. \& } \\
\text { Willetts } \\
\text { Forceps }\end{array}$ & $\begin{array}{c}\text { Caesarean } \\
\text { Section }\end{array}$ & $\begin{array}{l}\text { Ver- } \\
\text { sion }\end{array}$ & Breech & Nil \\
\hline I & 48 & 3 & 4 & I & 4 & I I \\
\hline 2 & 25 & 9 & 20 & 7 & 2 & 4 \\
\hline 3 & I & I I & 43 & 17 & I & - \\
\hline 4 & $\tau$ & 2 & 60 & - & I & I \\
\hline
\end{tabular}

Table 6 illustrates the method of treatment in 275 cases according to the degree of placenta praevia and shows that as the severity of the degree increases the number of Caesarean sections rise.

Having decided on Caesarean section as the best method of treatment one should still have an open mind as to which type of operation is more 
appropriate. In the majority of cases the lower segment operation can be performed and, taking the long view of future pregnancies, is preferable. There are, however, cases where the lower segment is narrow or inaccessible and in such cases the classical operation, is safer. If a subumbilical incision is made initially either operation may be performed with ease. If haemorrhage has occurred during or following the vaginal examination a blood transfusion should be started simultaneously with the Caesarean section.

The group of patients in which the haemorrhage has been more than moderate or has persisted presents a difficult problem. These cases as a rule occur in the groups of second or third degree placenta praevia, and in many of the cases the baby is immature or already dead. In the writer's experience these cases account for the greatest number of foetal deaths (see Table 5).

If the baby is alive and not too premature a Caesarean section should be performed. When it is immature or dead a podalic version will usually control the haemorrhage.

In most cases the latter method of treatment is possible as the cervix will be found to admit at least one finger, and usually two, allowing a foot to be extracted.

Table 7 shows the results associated with the various methods of treatment. It has been suggested that the increased use of Caesarean section as a method of treatment may result in difficulty and danger at future confinements. The practice of doing the lower segment, in preference to the classical. operation diminishes the risk of uterine rupture at a subsequent confinement.

In 15 cases in the personal series where lower
TABLE 7

Results of Various Methods of Treatment

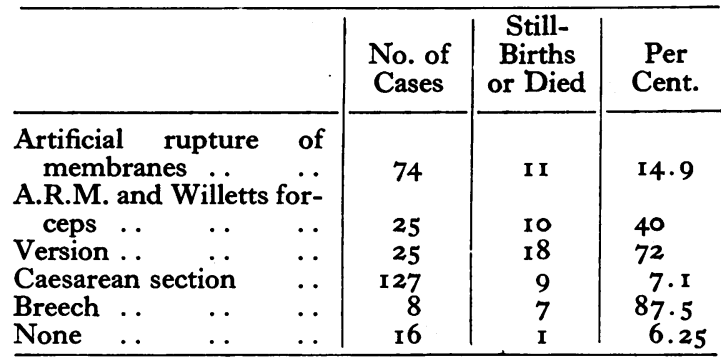

segment Caesarean section was performed, 12 cases were delivered per vaginum at their subsequent confinemerts and three had Caesarean section, one for another placenta praevia and two on account of contracted pelves.

While there has been an improvement in the results of the treatment of placenta praevia, there appears to be a limit to what one can attain as far as the baby is concerned, and it is possible that the foetal death rate cannot be reduced below 12 to 16 per cent.

To maintain or improve the results requires constant vigilance and the full use of every assistance one can get from blood transfusion, paediatric and nursing services.

\section{REFERENGES}

I. JOHNSON, H. W. (1945), Am. F. Obst. Gyn., 50, 248-254.

2. MIELS, W. G. (1948), Brit. Med. F., 2, 896.

3. MACAFEE, C. H. G. (1945), F. Obst. Gyn. Brit. Emp., 52, 3 I 3.

4. MACAFEe, C. H. G. (1945), Proc. Roy. Soc. Med., 39, 9.

5. STURROCK, J., STIRLING, H., TENNENT, R. A. (1947), Edin. Med. Э., 54, 496, 504, 5 I0.

6. BROWNE, F. J. (1946), 'Antenatal and Postnatal Care,' 6th ed., Churchill, London.

\section{WILLIAM SMELLIE}

William Smellie was born in Lanark in 1697 of ' substantial people.' He was educated in the local Grammar School, to which he subsequently left his books. He first set up practice in Lanark in 1720 having served his apprenticeship in Glasgow. In 1739 he travelled to London (with letters of introduction from Professor Monro in Edinburgh) and later studied under Gregoire in Paris. He then settled in London to teach midwifery in his own house, using a model made of pelvic bones covered in leather, and rapidly became well known in spite of a somewhat uncultivated bearing. His great contributions to obstetrics were the introduction of curved forceps with rules for their proper application, and the introduction of pelvic measurement in the identification of contracted pelvis. He became the close friend of Smollet and William Hunter was one of his pupils.

He died in Lanark whilst awaiting the publication of the third volume.of his case notes in 1763 . 